\title{
SPECTROSCOPIC STUDIES ON $\mathrm{Cd}^{2}+$ BINDING TO HUMAN ERYTHROCYTE SPECTRIN
}

\author{
Hong-Ye Sun, Xiao-Li Ma, Tao Wang, Rong-Chang Li and Kui Wang* \\ Inorganic Chemistry Department, School of Pharmaceutical Sciences, \\ Beijing Medical University, Beijing 100083, China
}

\begin{abstract}
The binding of $\mathrm{Cd}^{2+}$ to the human erythrocyte spectrin tetramer ( $\left.\mathrm{SPT}\right)$ and the consequent conformation change were studied as a function of the $\mathrm{Cd}^{2+} / \mathrm{SPD}$ mole ratio ( $R$ ) by fluorescence and circular dichroism (CD) spectra. The conformation dependence on $\mathrm{R}$ has a biphasic feature: in the range less than 60 , the $\mathrm{Cd}^{2+}$ ions are likely bound to a small fraction of the thiol groups and the non-thiol groups on the surface of SPT and the conformational changes are not significant as characterized by the labeled $\mathrm{N}$-(1-pyrenyl)maleimide (NPM)fluorescence and $C D$ spectra. When $R$ reaches 60 , as a result of a conformational change, the SH-related strong binding sites are exposed and bind with $\mathrm{Cd}^{2+}$. The biphasic conformational change at this turning point might be interpreted on the basis of thiol groups as critically important for maintaining the secondary structure of SPT.
\end{abstract}

\section{Introduction}

The membrane skeleton of erythrocyte plays an important role for the maintance of the cell activity. [1] Spectrin, as a major component of the skeleton network, is composed of heterodimeric subunits $\alpha[250 \mathrm{KD}] \beta[230 \mathrm{KD}]$. The dimer associates in a head-to-head mode to form $200 \mathrm{~nm}$ long tetramer (SPT), which is the predominent state of spectrin in erythrocyte cells ${ }^{[2]}$. It is known that metal ions such as $\mathrm{Ca}^{2+}, \mathrm{Mg}^{2+}$ and $\mathrm{Tb}^{3+}$ tend to bind to spectrin and alter its self-association state. The metal ions thus studied are all hard acid ions. ${ }^{[3-11]} \mathrm{Li}$ et al studied the effect of platinum complexes on the conformation of spectrin. ${ }^{12 I}$ Yang et al 
reported the interactions between $\mathrm{SeO}_{3}{ }^{2-}$ and spectrin. ${ }^{[13-15]}$ It might be expected that the binding with soft cations and the consequent conformation change are different from hard ones act. For this sake, we studied the $\mathrm{Cd}^{2+}-\mathrm{SPT}$ interactions by measurement of the fluorescence spectra, both intrinsic and SH-labeled SPT and the CD spectra.

\section{Methods and materials}

Materials. Fresh human blood was obtained from the Beijing Blood Central Bank. Other reagents are all of analytical grade.

\section{Purification of spectrin}

Human erythrocyte ghosts were prepared acording to Dodge ${ }^{[16]}$ and spectrin was purified according to the Gratzer method ${ }^{[17]}$ with some modifications. After extraction with a very low ionic strength buffer ( of $0.3 \mathrm{mM}$ phosphate, $0.1 \mathrm{mM}$ EDTA and $0.1 \mathrm{mM}$ PMSF pH 7.5), the suspension was dialyzed against the same buffer at $4^{\circ} \mathrm{C}$. The suspension was then centrifuged at 17,000rpm for $30 \mathrm{~min}$. and the supernatant was centrifuged again at the same condition to remove the vesiculated membranes completely. The supernatant was concentrated by dialysis against polyethylene glycol (Mr.20KD) and then applied to a column of Sepharose 4B $2.5 \times$ $80 \mathrm{~cm}$. A pH 7.4 buffer consisting $130 \mathrm{mM} \mathrm{KCl}, 20 \mathrm{mM} \mathrm{NaCl}$, ImM EDTA, 10 $\mu \mathrm{M}$ DTT and $0.5 \mathrm{mM} \mathrm{NaN} \mathrm{Na}_{3}$ was used for elution. The SPT peak was pooled down and reapplied to the column to collect the purified spectrin. The spectrin solution was dialyzed exhaustively against a pH8.0 buffer containing $2 \mathrm{mM}$ EDTA and the procedure was repeated three times and then dialyzed against the deionized water to remove the EDTA. Finally, the spectrin solution was immediately dialyzed against the appropriate buffer. The spectrin concentration were determined spectrophotometrically $(E 1 \% \mathrm{lcm}=10.7)$ and checked with Lowry's method. They are calculated and expressed as those of SPD. $\mathrm{CdCl}_{2}$ stock solution is $1.6 \mathrm{mM}$. Without specification, all the buffers used are composed of $0.1 \mathrm{M} \mathrm{NaCl}, 0.05 \mathrm{M}$ Tris- $\mathrm{HCl}$ and $\mathrm{pH}$ 7.4.

\section{Fluorescence measurements}

All the steady state fluorescence measurements were conducted with a Hitachi 3000 spectrophotofluorometer at $22^{\circ} \mathrm{C}$. Slits for both excitation and emission were set at $5 \mathrm{~nm}$.

\section{Intrinsic fluorescence}

In typical experiments, $\mathrm{SPT}(0.26 \mu \mathrm{M})$ solutions were titrated with $\mathrm{CdCl}_{2}$ stock solution. The final volume change was less than $5 \%$. The $\mathrm{Cd}^{2+}$ concentration is in the range of $1.48 \times 10^{-6}$. $1.48 \times 10^{-5} \mathrm{M}$, and the samples were excited at $280 \mathrm{~nm}$ and emission was measured at $340 \mathrm{~nm}$. 


\section{NPM labeled fluorescence}

The $C d^{2+}-S P T$ complexes labeled with NPM. Various volumes of the $\mathrm{CdCl}_{2}$ stock solution were added to a series of SPT $(0.26 \mu \mathrm{M})$ solution. After standing at room temperature for $4 \mathrm{hr}, 10 \mu \mathrm{l}$ $3 \mathrm{mM}$ NPM stock solution was added to the solutions, and set them overnight at $4^{\circ} \mathrm{C}$. The samples were excited at $342 \mathrm{~nm}$ and the emission fluorescence was measured at $375 \mathrm{~nm}$.

The titration of NPM-SPT with $C d^{2+} 200 \mu \mathrm{l} 3 \mathrm{mM}$ NPM solution was added to $50 \mathrm{ml} 0.47 \mu \mathrm{M}$ SPT solution . After standing overnight at $4^{\circ} \mathrm{C}$ and dialyzing against the same buffer to remove the free NPM, the solution was centrifuged at $18,000 \mathrm{rpm}$ at $4^{\circ} \mathrm{C}$ for $1 \mathrm{hr}$. The NPM-SPT was titrated with $\mathrm{CdCl}_{2}$ by adding various volumes of $\mathrm{CdCl}_{2}$. stock solution to $2.5 \mathrm{ml}$ of the NPMSPT solution. After standing for $4 \mathrm{hr}$, the fluorescence spectra were recorded.

Circular dichroism measurements Measurements were performed on an Jasco-20 Polarizing Spectrophotometer. SPT concentration was diluted to $0.125 \mu \mathrm{M}$ using the buffer and the spectra were scanned from 260 to $190 \mathrm{~nm}$. $\mathrm{Cd}^{2+}$ concentration in the samples varied from 0 to $1.4 \times 10^{5} \mathrm{M}$.

\section{Results}

(1) Intrinsic fluorescence As shown in Fig.1, the fluorescence intensity was reduced in the course of the $\mathrm{Cd}^{2+}$ titration. Since the fluorescence of SPT is mainly due to tryptophane residues, this result indicates that the microenvironment of tryptophane in SPT was changed by the binding of $\mathrm{Cd}^{2+}$, which makes the tryptophane residues exposed to the aqueous media.

(2) NPM labeled $\mathrm{Cd}^{2+}-\mathrm{SPT}$ complexes When the SPT treated previously with $\mathrm{Cd}^{2+}$ was labeled with NPM , NPM reacts with the thiol groups unoccupied by $\mathrm{Cd}^{2+}$. The results revealed that the fluorescence intensity decreases slightly in the range of $R$ less than 60 , but the intensity decreased significantly with R higher than 60 (Fig. 2). NPM is a highly specific reagent for thiol group. Because it is not fluorescent in the free form, and turns to be fluorescent when covalently linked with the thiol groups of the protein, the number of free thiol groups of the protein can be deduced on the basis of its fluorescence intensity. Base on the results of NPM labeling studies of $\mathrm{Cd}^{2+}-\mathrm{SPT}$ complexes, $\mathrm{Cd}^{2+}$ ions are bound to a very small fraction of thiol groups at low $\mathrm{Cd}^{2+}$ concentration. The dramatic reduction in the intensity at higher $\mathrm{Cd}^{2+}$ concentration indicates that $\mathrm{Cd}^{2+}$ ions mainly bind to thiol groups and left only a small number of thiol groups to link with NPM. It is reasonable to say that the conformation change at low $\mathrm{R}$ value clears the way for more $\mathrm{Cd}^{2+}$ ions binding to thiol groups. Yang et al have 


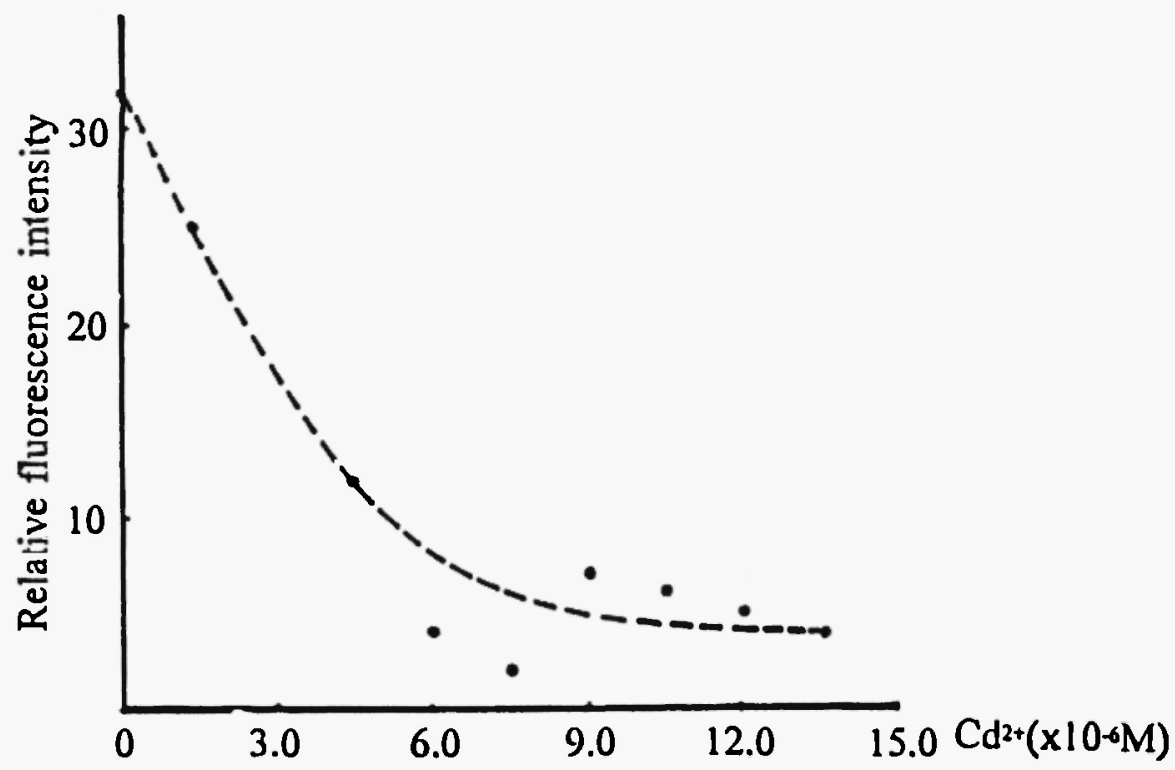

Figure 1 Effect of cadmium on intrinsic fluorescence of SPT Csp $=0.26 \mu \mathrm{M}$, buffer: $0.1 \mathrm{M} \mathrm{NaCl}, 0.05 \mathrm{M}$ Tris$\mathrm{HCl} \mathrm{pH} \mathrm{7.4.}$

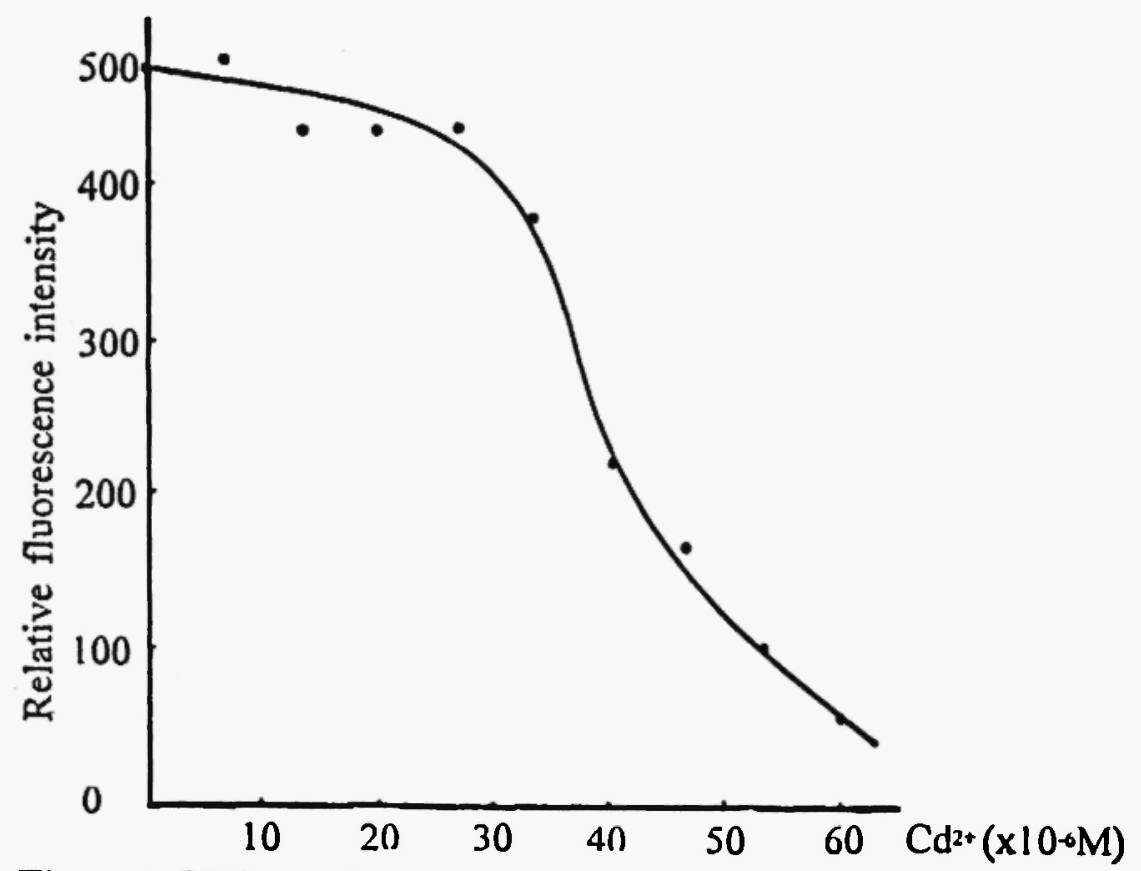

Figure 2 SP' $\Upsilon$ was titrated with $\mathrm{Cd}^{2+}$ and then saturared with NPM

Csp $=043 \mu \mathrm{M}$, buffer $: 0.1 \mathrm{M} \mathrm{NaCl}, 0.05 \mathrm{M}$ Tris- $\mathrm{HCl}$ pH 7.4 
observed similar result in case of the interactions between SPT and $\mathrm{SeO}_{3}{ }^{2-[11-13]}$, but it has not been interpreted.

(3) NPM lablled SPT titrated by $\mathrm{Cd}^{2+}$ NPM is frequently employed as a probe for conformation changes related to the microenvironment of thiol groups in proteins. As shown in Fig. 3, the fluorescence of NPM-SPT was quenched slightly in the course of titration in lower $\mathrm{Cd}^{2+}$ concentration, but as the $\mathrm{R}$ value increases over 60 , the fluorescence was quenched abruptly. It reveals that $\mathrm{Cd}^{2+}$ binding makes the NPM labeled on the thiol groups turns from hydrophobic to hydrophilic environment.

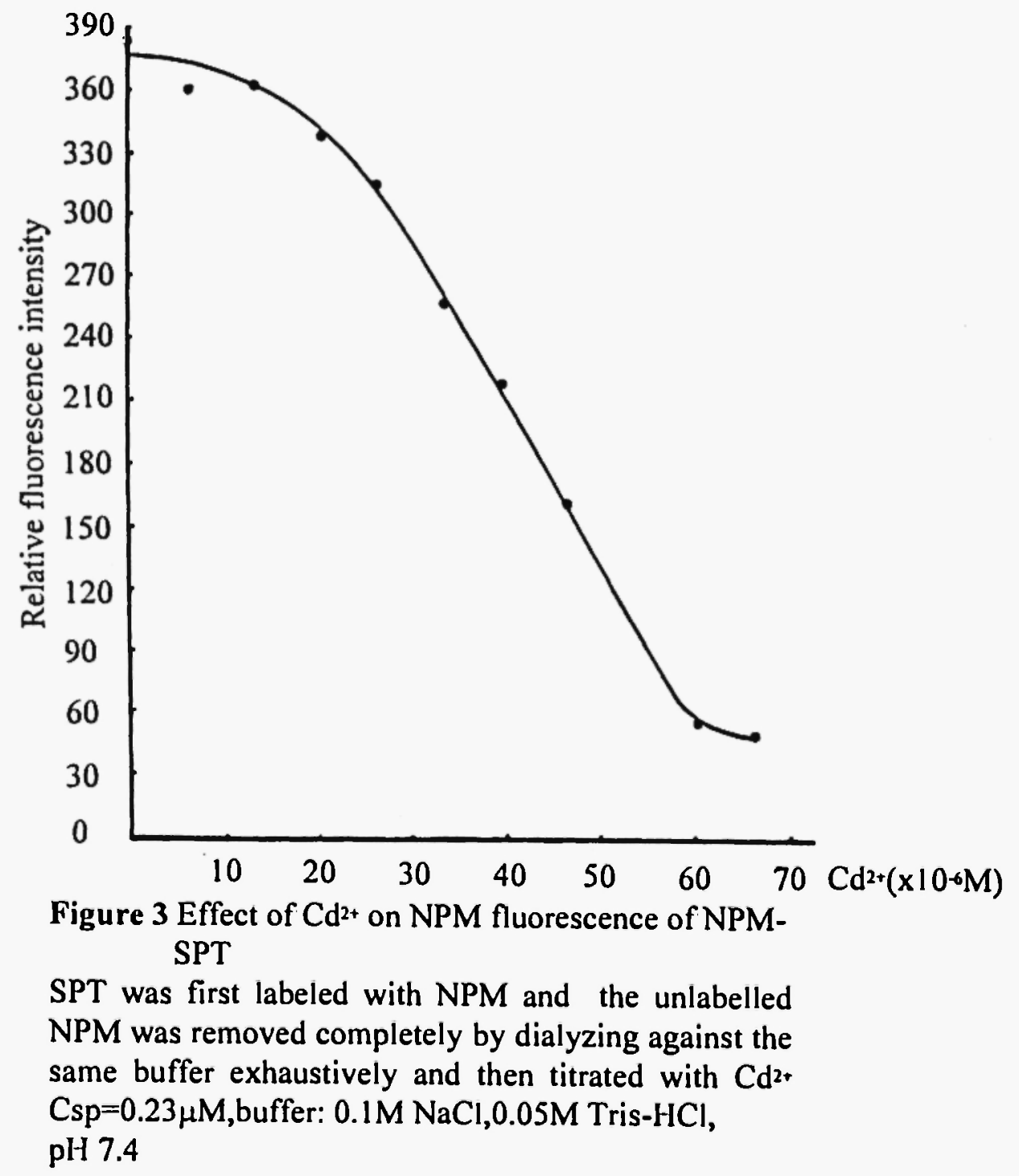

(4) CD spectra The CD spectra of SPT, characterized by two negative peaks at $208 \mathrm{~nm}$ and $220 \mathrm{~nm}$,are typical $\alpha$ helix-rich protein. The molar ellipticity $\theta_{208}$ is dependent on the 
$\mathrm{Cd}^{2+}$ concentration . From the titration curve (Fig.4), it can be seen that following the increasing of the $\mathrm{Cd}^{2+}$ concentration. $\theta_{208}$ values move towards slightly negative value. When $\mathrm{R}$ value is

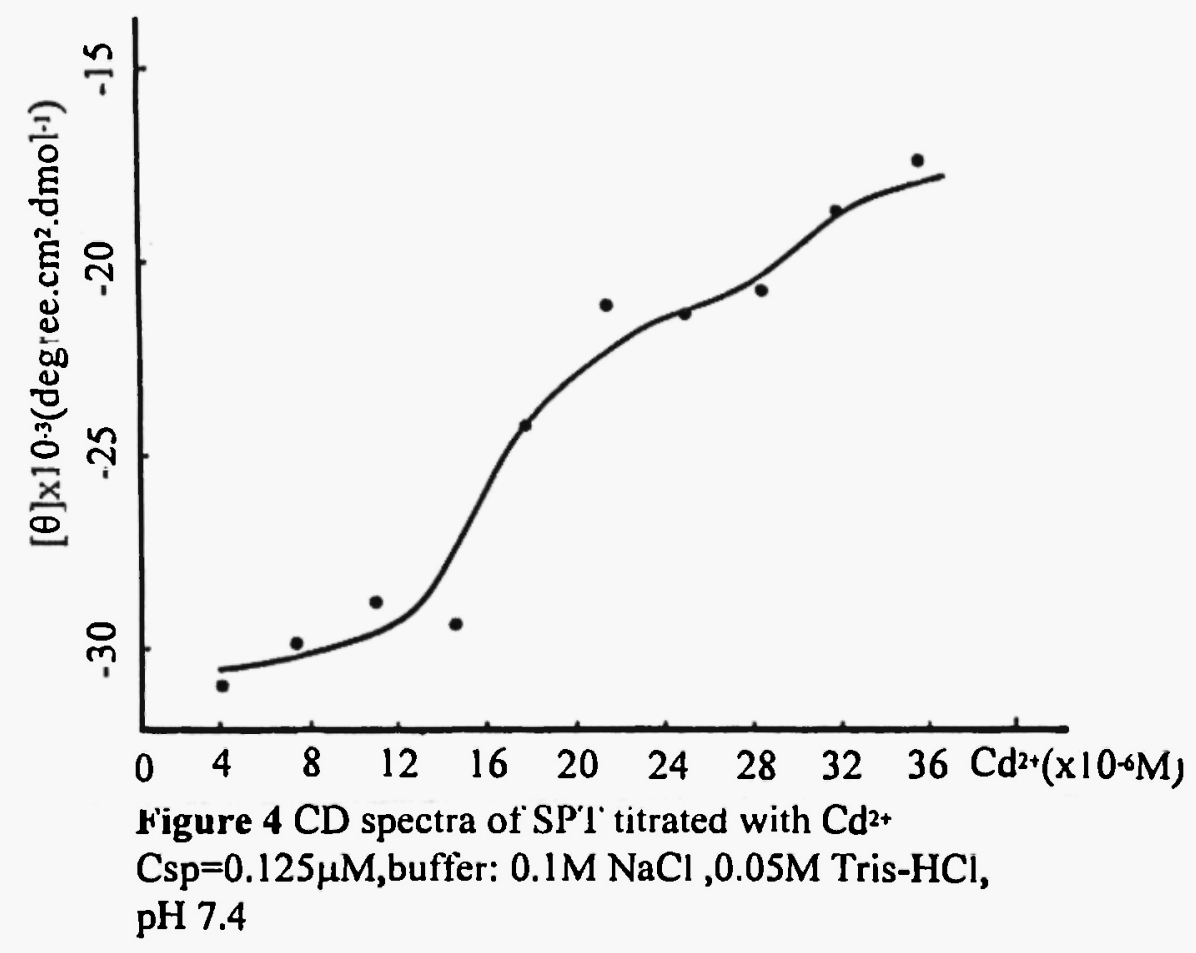

higher than 60 ,the changes become more significant. This indicates that the $\alpha$-helix contents are decreased when $\mathrm{Cd}^{2+}$ increases. These results indicate that a low $\mathrm{Cd}^{2+}$ concentration has only a small effect on the secondary structure of spectrin. However, high $\mathrm{Cd}^{2+}$ concentration destroys it.

\section{Discussion}

The interaction between $\mathrm{Cd}^{2+}$ and SPT is featured by a biphasic stage as a function of $\mathrm{R}$ and $\mathrm{R}=60$ is the turning point. When $\mathrm{R}$ is below 60 , only a slight conformation change was observed as shown by the low quenching of intrinsic fluorescence and NPM labeled fluorescence. When the $R$ is raised to above 60 , the conformation changes abruptly. This biphasic feature might be explained as follows: $\mathrm{Cd}^{2+}$ ions bind to a small fraction of the thiol groups and the carboxylic groups on the surface of SPT moleules at first, and the thiol groups which are of high affinity to $\mathrm{Cd}^{2+}$, are buried in SPT molecules. The $\mathrm{Cd}^{2+}$ binding to the surface carboxylic groups resulted in only little conformation change, Nevertheless, the binding 
facilitates the burried thiol groups to turn out to more open sites, exposing them to attacking $\mathrm{Cd}^{2+}$ ions. The conformation changes significantly beyond the turning point, which makes a large number of $\mathrm{Cd}^{2+}$ ions to bind to the thiol groups of SPT. These results demonstrate that the thiol groups are very important in maintaining the secondary structure of SPT. In this case, $\mathrm{Cd}^{2+}$ binding in the first stage results in a conformation to facilitate $\mathrm{Cd}^{2+}$ binding to more thiol groups when $\mathrm{R}$ reaches a critical value. This might be considered as a special case of cooperative effect among different binding groups. The present works show that the fluorescence labeling method is helpful to get an insight to the metal ion binding to proteins.

Our previous study on the interaction between $\mathrm{Tb}^{3+}$ and SPT shows that $\mathrm{Tb}^{3+}$ binds to SPT in a monophasic mode .This is reasonable because the hard acid $\mathrm{Tb}^{3+}$ binds to carboxylic groups solely. The difference in hardness of these ions causes binding to different binding groups of the protein and thus induces different conformation change of SPT.

\section{References}

[1] S.R. Goodman, and S.Kathleenr, Am. J. Physiol., 244, c121-c141(1983)

[2] D.M. Shotton, B. Burke and D. Braton, J. Mol. Biol., 131, 303-329(1979)

[3] E. Brauer, K.D. Kupka and V. Rudloff, Bioelectrochem. Bioenerg., 3, 509-518(1976)

[4] B. Lamel and G. Maier, Biochim. et Biophys. Acta, 622,245-258(1980)

[5] C.J. Wallis, E.F. Wenegieme and J.A. Bahitch, J. Biol. Chem., 267(7), 4333-7(1992)

[6] S.Lundberg, V.-P. Lehto and L. Backman, Biochemistry, 31, 5665 (1992)

[7] C.J. Wallis, E.F. Wenegieme and J.A. Babitch, Biochemistry, 32, 5045(1992)

[8] H.-Y. Sun,H.-K. Lin, Y. Cao, R.-C. Li, K. Wang, R.-T. Chen, J. Inorg. Biochem. Submitted

[9] G.H. Beaven, and W.B. Gratzer, Biochim. et. Biophys. Acta., 600,140-149 (1980)

[10] W.B. Gratzer, G.B. Beaven, Eur. J. Biochem., 558, 403(1975)

[11] G.H. Beaven, J. Parmar, G.B. Nash, P.M. Bennett and W.B. Gratzer, J. Membrane Biol, $118,251=57(1990)$

[12] R.-C. Li, H.-Q. Cai, X.-G. Yang, B.-W. Chen, K. Wang, Journal of Beijing Medical University, 24(6), 481(1992)

[13] J. Yang and F.-Y. Yang, Acta Biophysica Sinica, 4(4), 372 (1988)

[14] M.-Z. Yang and F.-Y. Yang, Acta Biophysica Sinica, 4(4), 379(1988)

[15] F.-Y. Yang ,J. Yang, Z.-M. Liu, BioFactors , 3(1), 49(1991)

[16] I.T. Dodge, C. Mitchell and D.J. Hanahan, Arch. Biochim. Biophys, 100, 119(1963)

[17] W.B. Gratzer, Methods In Enzymology, 85, 475(1982)

Received: May 25, 1994 - Accepted: June 15, 1994 - Received in revised camera-ready format: July 5, 1994 
